\title{
Optimized Synthesis of Molecularly Imprinted Hybrid Polymer by Factorial Design for Selective Caffeine Extraction in Surface Water
}

\author{
Fabiana Casarin, ${ }^{a}$ Camila S. Dourado, ${ }^{a}$ Luana S. Sousa, ${ }^{a}$ Marco T. Grassi ${ }^{\circledR b}$ and \\ Ana C. B. Dias ${ }^{\circledR} *, a$ \\ aInstituto de Química, Universidade de Brasília, Campus Darcy Ribeiro, 70910-900 Brasília-DF, Brazil \\ ${ }^{b}$ Departamento de Química, Centro Politécnico, Universidade Federal do Paraná (UFPR), \\ Jardim América, CP 19032, 81531-980 Curitiba-PR, Brazil
}

\begin{abstract}
A hybrid imprinted polymer (HMIP) was synthetized via sol-gel technique in aqueous solution for caffeine separation from environmental waters samples. The optimal conditions of synthesis were stablished by application of a $2^{3}$ full factorial experimental design with three factors: ratio of functional monomer and cross-linker reagent, and acid or basic catalyst $\left(\mathrm{HCl}\right.$ or $\left.\mathrm{NH}_{4} \mathrm{OH}\right)$. The HMIP obtained with the factorial designs was 22.5 times more selective for caffeine than control polymer, with an adsorption mechanism of pseudo-second order with two sorption sites. The maximum equilibrium adsorption capacity was $1.91 \mathrm{mg} \mathrm{g}^{-1}$ that was maintained until ten cycles of reuse, indicating their excellent stability. The material was 21 times more selective for caffeine than for its analogous molecules (theophylline and theobromine). HMIP was applied in solid phase extraction (SPE) procedure and caffeine extraction of surface water had good recoveries (93.0\%). These results demonstrated that the factorial experimental design resulted in an efficient and selective sorbent for caffeine with a reduction of number of synthesis and problems of trial-and-error protocol as well as reagents consumption decrease.
\end{abstract}

Keywords: molecularly imprinted polymer, factorial experimental design, hybrid synthesis, caffeine, water

\section{Introduction}

Some Brazilian water sources that supply large urban centers have presented low quality indices due to the ineffectiveness of water and sewage treatments that is directly associated to the anthropogenic contaminants released into the water. ${ }^{1}$ These contaminants, classified as emerging contaminants (EC), have become a main target in the assessment of water quality around the world, ${ }^{1-3}$ since their occurrences and effects have not yet been fully elucidated.

Due to the complexity of water matrix, the selection of markers, as tracers of anthropic activity, became an excellent option to indirect determination of the emerging contaminants. ${ }^{4}$ The choice of a suitable tracer must take into consideration the regular consumption by the population and the possible transfer of the contaminants to sewage systems. Several studies ${ }^{1,3,4}$ have shown that caffeine $(\mathrm{CAF})$ is an appropriate anthropogenic indicator because is

*e-mail: acbdias@gmail.com present in a wide range of consumer products such as food, beverages, and medicines. Moreover, CAF have adequate physical-chemical properties to its determination and quantification, such as, high solubility in water $\left(13.5 \mathrm{~g} \mathrm{~L}^{-1}\right)$, low octanol-water partition coefficient $\left(\log \mathrm{K}_{\mathrm{ow}}=0.01\right)$ and low volatility. ${ }^{5}$

CAF determination has been performed by separation techniques such as liquid (LC) and gas (GC) chromatography coupled to mass spectrometric detection. ${ }^{5}$ However, due to the complexity of the water samples and the low concentrations of CAF, sample preparation methods that combine extraction and preconcentration are required. Usually, sample preparation methods are performed by solid phase extraction (SPE), which presents a high enrichment factor, easy mechanization, and low consumption of organic solvents. ${ }^{6}$ Commercial solid phases are generally used to extract a specific class of molecules and/or to clean-up the sample matrix, requiring a posteriori separation technique to improve selectivity. Given this, some research involving synthesis of sorbent materials with high sorption capacity and selectivity has been developed, ${ }^{7}$ such as molecularly 
imprinted polymers (MIP). ${ }^{8}$ These polymers are widely used as selective solid phase because their polymeric structure is synthesized for a specific molecule. The mechanism is based on the complexation of the analyte used as template (T) by functional monomers (FM) through non-covalent bonds, then, after equilibrium the complex is polymerized by addition of a crosslinker reagent (CL). After synthesis, the template is extracted resulting in threedimensional cavities with specific bonding sites available for the analyte rebinding., 90 Thus, due to their "memory effect" and high stability they can be widely used as highly selective materials in extraction procedures. ${ }^{10-12}$

MIP can be composed of organic or inorganic polymeric network with a variety of functional monomers depending on the application. MIP made exclusively by organic compounds are synthesized by free radical reactions and have high adsorptive capacity and porosity. However, due to the organic matrix, a poor water compatibility and high capacity of swelling when exposed to different extraction solvents are generally observed., ${ }^{913-16}$ On the other hand, inorganic polymers that are exclusively made of orthosilicic acid $\mathrm{Si}(\mathrm{OH})_{4}$ via sol-gel process, presents high water compatibility and high thermal stability but have a more fragile polymeric network that can crack or shrink during the extraction. ${ }^{17-19}$

An approach that combines the benefits of organic and inorganic synthesis compounds have been the use of hybrid functional monomers, composed by organic and inorganic functional groups. ${ }^{17,20,21}$ It can be used to solve some drawbacks mainly when aqueous samples are applied during the template extraction. The hybrid functionality can be defined in several ways, such as the presence of organic groups in inorganic monomer in a sol-gel process, the presence of inorganic group in organic monomer in a radical polymerization and the sol-gel process coupled to radicalar polymerization, being the last considered also as hybrid synthesis. ${ }^{22}$ Considering the aqueous medium, a hybrid functional monomer on a silicate-based networks are more suitable, as they facilitate the template mass transport to the cavities and the organic group promotes the specific and strong bonding with the template. ${ }^{20,21}$ Then, considering CAF extraction in water samples, this hybrid molecularly imprinted polymer (HMIP) is an excellent approach.

Regarding the silicate polymeric network, the sol-gel process is one of the simplest, however, as any procedure, requires studies involving different parameters, such as kind of FM and porogen solvents, $\mathrm{pH}$, and molar proportion between T, FM and CL. For each parameter evaluated is obtained a polymer with unique morphological and physicochemical characteristics, as well as a different selectivity factor. ${ }^{23}$ Usually, the optimization is carried out by univariate optimization methods, which result in many syntheses, high consumption of chemical reagents and time. Besides that, the univariate methods do not consider codependent variables once that just one parameter is changed at time. Then, the application of multivariate factor optimization methods might be an interesting approach when new HMIP are in development. The application of statistics methods has many advantages such as significant reduction in number of synthesis and consequently reduction of cost and time and the capacity to study several variables at the same time with good accuracy and precision. ${ }^{24-26}$

Then, the present work has as objective the application of a factorial design optimization to obtain the most adequate experimental condition to synthesize a HMIP by a sol-gel process for $\mathrm{CAF}$ extraction. Aminopropyltrimethoxysilane (APTMS) was used as a hybrid monomer that provides both efficient non-covalent bonds with CAF and application in aqueous media. HMIP was used as solid extractor in a SPE procedure for CAF determination in surface water.

\section{Experimental}

\section{Reagents}

All chemical reagents and solvents were analytical grade. Aminopropyltrimethoxysilane (APTMS), tetraethoxysilane (TEOS) were purchased from SigmaAldrich (Saint Louis, USA). Caffeine, theophylline (TEP) and theobromine (TEB) were purchased from SigmaAldrich (Steinheim, Germany). Methanol (MeOH) HPLC grade (Tedia, Fairfield, USA), hydrochloric acid $(\mathrm{HCl})$ (Biograde, San Francisco, USA) and ammonium hydroxide $\left(\mathrm{NH}_{4} \mathrm{OH}\right)$ (Biograde, San Francisco, USA) were acquired as analytical grade solvents. All the solutions in this work used deionized water $(\geq 18 \mathrm{M} \Omega \mathrm{cm}$ ) produced by the purification system Milli-Q ${ }^{\circledR}$ Reference (Merck, Millipore, Darmstadt, Germany).

\section{Instrumentation and experimental procedure}

A magnetic stirrer (AA-840, Gehaka, São Paulo, Brazil) was used for sol-gel process. The sorption experiments were performed in an orbital hematological homogenizer (Labor, ALB 260 H, São Paulo, Brazil) operated at 25 rpm and for solution separation was used a centrifuge (KC5, Kindly, Brazil) operated at $4000 \mathrm{rpm}$. Infrared spectra were obtained with a Fourier transform infrared (FTIR) spectrometer (640-IR, Agilent, Santa Clara, USA), operating in a transmission mode between 4000 and $400 \mathrm{~cm}^{-1}$. The morphology of the polymers was evaluated 
by scanning electron microscopy (SEM) using the scanning electron microscope (FEI Quanta 200-3D, Tokyo, Japan). Thermal analysis was performed by a thermogravimetric analyzer (DTC-60 H, Shimadzu, São Paulo, Brazil), in a range of 25 to $1000{ }^{\circ} \mathrm{C}$ at $10^{\circ} \mathrm{C} \mathrm{min}^{-1}$, in synthetic air. The porosity and specific surface areas of the polymers were evaluated by $\mathrm{N}_{2}$ sorption porosimetry tests by exposing the polymer to $100{ }^{\circ} \mathrm{C}$ for $3 \mathrm{~h}$ in vacuum (Surface Area and Pore Size Analyzer, 2200c, Quantachrome, Florida, USA).

For molecularly imprinted solid phase extraction (MISPE) procedure was used a peristaltic pump (Ismatec IPC, Glattzbrugg, Switzerland) with Viton tubes $(2.06 \mathrm{~mm}$, internal diameter, Cole-Parmer Instrument Co, Vernon Hills, USA).

For separation and determination of CAF, a highpressure liquid chromatograph (HPLC) with UV detection at $272 \mathrm{~nm}$ was used (LC-20A, Shimadzu, Prominence, Japan). Separations were performed on a C-18 reverse phase column (dimensions: $250 \times 4.6 \mathrm{~mm}$, $5.0 \mu \mathrm{m}$ particle diameter, Browniee Analytical PerkinElmer, Waltham USA). The method was based on studies by Machado $e t a l .^{3}$ with slightly changes, using the mobile phase, methanol:water (40:60) at a flow rate of $0.8 \mathrm{~mL} \mathrm{~min}^{-1}$ and injection of $100 \mu \mathrm{L}$ of standard/samples. The separation procedure was conducted by binary gradient according to the following schedule: from 0 to $1 \mathrm{~min}, 10 \% \mathrm{MeOH}$ and $90 \%$ water and gradually increasing from 1 to $2 \mathrm{~min}$, resulting in $40 \% \mathrm{MeOH}$ and $60 \%$ of water at the end of two minutes. From 2 to $8 \mathrm{~min}$, the gradient was kept at $40 \%$ methanol and $60 \%$ water, decreasing to $10 \%$ at $8 \mathrm{~min}$. Initial conditions were restored within $2 \mathrm{~min}$, resulting in a total of $12 \mathrm{~min}$ for chromatographic analysis. The calibration curve was obtained in the range 5.0 to $750 \mu \mathrm{g} \mathrm{L}-1$ (coefficient of determination $\left(\mathrm{R}^{2}\right)=0.9988, \mathrm{n}=3$ ).

\section{HMIP synthesis}

The procedure optimized by the factorial design consisted of mixing $4 \mathrm{mmol}$ of CAF, $10 \mathrm{~mL}$ of distilled water and 2 mmol APTMS in a beaker until complete solubilization. Then, $200 \mu \mathrm{L} \mathrm{NH}_{4} \mathrm{OH}$ and $8 \mathrm{mmol}$ TEOS were added. The mixture was heated under stirring at $40{ }^{\circ} \mathrm{C}$ until gelation resulting in an opaque white monolith. The polymer was aged at room temperature for $72 \mathrm{~h}$. Subsequently, it was oven dried at $120^{\circ} \mathrm{C}$ for $2 \mathrm{~h}$ and then macerated and sieved, resulting in particles between 56 and $126 \mu \mathrm{m}$. Thereafter, the template molecule was removed by exhaustive washing with methanol at a ratio of $40 \mathrm{~mL}$ to each $1.0 \mathrm{~g}$ of HMIP and monitored by UV-Vis spectrophotometry. Finally, the HMIPs were oven dried at $120^{\circ} \mathrm{C}$ and stored for later application. In parallel, the hybrid non-imprinted polymer (HNIP) was prepared by the same procedure without the addition of the template molecule.

\section{Experimental design}

The experimental design was applied to verify the effect of different synthesis variables on HMIP sorption capacity in relation to the control polymer (HNIP), denominated as impression factor (IF, equation 1).

$$
\mathrm{IF}=\frac{\mathrm{Q}_{\mathrm{HMIP}}}{\mathrm{Q}_{\mathrm{HNIP}}}
$$

where $\mathrm{Q}_{\text {HMIP }}$ is the sorption capacity of hybrid imprinted polymer and $\mathrm{Q}_{\mathrm{HNIP}}$ sorption capacity of hybrid nonimprinted polymer.

In this study, a factorial design $2^{3}$ was applied to evaluate the influence of three factors: molar ratio of FM and CL (APTMS:TEOS), and acid or basic catalyst $(\mathrm{HCl}$ or $\left.\mathrm{NH}_{4} \mathrm{OH}\right)$. These were chosen as independent variables, in two levels, expressed as coded values $(+1$ and -1$)$, and were considered for each of the three factors under investigation. Table 1 shows the coded and decoded levels of the experimental design. HMIP was synthesized as describe before and the other synthesis conditions were kept constant throughout the study. Statistical treatment of the experimental design stage was performed using Statistica version 7.0 software. ${ }^{27}$

Table 1. Matrix of factorial design $\left(2^{3}\right)$ with factors and levels investigated. Coded values at the two factors levels $(-1,+1)$ for the variables or factors studied are indicated in parentheses

\begin{tabular}{lccc}
\hline \multirow{2}{*}{ Experiment } & \multicolumn{3}{c}{ Factor } \\
\cline { 2 - 4 } & Catalyst & $\mathrm{FM} / \mathrm{mmol}$ & $\mathrm{CL} / \mathrm{mmol}$ \\
\hline 1 & $\mathrm{HCl}(-1)$ & $2(-1)$ & $4(-1)$ \\
2 & $\mathrm{NH}_{4} \mathrm{OH}(+1)$ & $2(-1)$ & $4(-1)$ \\
3 & $\mathrm{HCl}(-1)$ & $8(+1)$ & $4(-1)$ \\
4 & $\mathrm{NH}_{4} \mathrm{OH}(+1)$ & $8(+1)$ & $4(-1)$ \\
5 & $\mathrm{HCl}(-1)$ & $2(-1)$ & $8(+1)$ \\
6 & $\mathrm{NH}_{4} \mathrm{OH}(+1)$ & $2(-1)$ & $8(+1)$ \\
7 & $\mathrm{HCl}(-1)$ & $8(+1)$ & $8(+1)$ \\
8 & $\mathrm{NH}_{4} \mathrm{OH}(+1)$ & $8(+1)$ & $8(+1)$ \\
\hline
\end{tabular}

FM: functional monomer; CL: cross-linker reagent.

To estimate the IF parameter, experiments of sorption capacity (Q) were realized. For this, $20 \mathrm{mg}$ of each HMIP and HNIP produced as described above, was transferred into $15 \mathrm{~mL}$ Falcon tubes and $10 \mathrm{~mL}$ of $2.0 \mathrm{mg} \mathrm{L}^{-1} \mathrm{CAF}$ was added. The mixture was kept under stirring for $6 \mathrm{~h}$. At the end, the particles were removed by centrifugation 
(4000 rpm, $20 \mathrm{~min}$ ) and the solution was filtered and analyzed by UV-Vis spectrophotometry at $272 \mathrm{~nm}$.

The sorption capacity (Q) was calculated by equation 2 , from the difference between the initial concentration added and that found in the supernatant after sorption.

$\mathrm{Q}=\frac{\left(\mathrm{C}_{0}-\mathrm{C}_{\mathrm{s}}\right) \times \mathrm{V}}{\mathrm{m}}$

where Q: equilibrium sorption capacity $\left(\mathrm{mg} \mathrm{g}^{-1}\right), \mathrm{C}_{\mathrm{o}}$ : initial concentration of sorbate solution $\left(\mathrm{mg} \mathrm{L}^{-1}\right), \mathrm{C}_{\mathrm{s}}$ : equilibrium free sorbate concentration $\left(\mathrm{mg} \mathrm{L}^{-1}\right), \mathrm{V}$ : analyte solution volume (L) and m: mass in grams of the sorbent (HMIP or HNIP).

\section{Sorption studies}

The $\mathrm{pH}$ influence was verified using $20 \mathrm{mg}$ of HMIP and HNIP in Falcon tubes $(n=3)$, added $10 \mathrm{~mL}$ of $10.0 \mathrm{mg} \mathrm{L}^{-1}$ $\mathrm{CAF}$ and the $\mathrm{pH}$ adjusted with dilute $\mathrm{HCl}$ or $\mathrm{NaOH}$ solutions for different values (3.0, 5.0, 7.0 and 9.0). The tubes were placed in a mechanical shaker for $4 \mathrm{~h}$ and the supernatant solutions were analyzed.

The kinetics of CAF sorption in HMIP was evaluated with $20 \mathrm{mg}$ of HMIP weighed in Falcon tubes $(\mathrm{n}=3)$ with the addition of $10 \mathrm{~mL}$ of CAF $2.0 \mathrm{mg} \mathrm{L}^{-1}$ solution. The tubes were placed on a shaker and the solutions were removed at different time intervals $(10,15,30,45,60,90,120,180$ and $240 \mathrm{~min}$ ). The acquisition of adsorption kinetic parameters was performed by applying mathematical models to the empirical data obtained by the sorption experiments. The kinetic models applied were pseudo-first order and pseudo-second order models, according to equations 3 and 4 , respectively.

$\ln \left(Q_{e}-Q_{t}\right)=\ln Q_{e}-K_{1} t$

$\frac{\mathrm{t}}{\mathrm{Q}_{\mathrm{t}}}=\frac{1}{\mathrm{~K}_{2} \mathrm{Q}_{\mathrm{e}}^{2}}+\frac{1}{\mathrm{Q}_{\mathrm{e}}} \mathrm{t}$

where $\mathrm{Q}_{\mathrm{e}}$ : equilibrium sorption capacity, $\mathrm{Q}_{\mathrm{t}}$ : equilibrium sorption capacity at specific time, t: time of the study; $\mathrm{K}_{1}$ : rate constant of pseudo-first-order sorption process, $\mathrm{K}_{2}$ : kinetic constant of pseudo-second-order sorption.

The sorption equilibrium study was realized in different concentrations of CAF (1.0 to $20 \mathrm{mg} \mathrm{L}^{-1}$ ) and $20 \mathrm{mg}$ of HMIP added to Falcon tubes $(n=3)$. The tubes were placed in a mechanical shaker for $2 \mathrm{~h}$ and the solutions were analyzed. After equilibrium time, the mixture was centrifuged for $20 \mathrm{~min}$ at $4000 \mathrm{rpm}$ and the supernatants filtered and analyzed by HPLC-UV. The amount of sorbed CAF $\left(\mathrm{mg} \mathrm{g}^{-1}\right)$ was estimated according to equation 2 and the sorption parameters were obtained adjusting the data by the nonlinear Langmuir (equation 5), nonlinear Freundlich (equation 6), Langmuir-Freundlich isotherms at one site (equation 7) and Langmuir-Freundlich at two sites (equation 8).

$\mathrm{Q}_{\mathrm{e}}=\frac{\mathrm{K}_{\mathrm{L}} \mathrm{bC}_{\mathrm{e}}}{1+\mathrm{K}_{\mathrm{L}} \mathrm{C}_{\mathrm{e}}}$

$\mathrm{Q}_{\mathrm{e}}=\mathrm{K}_{\mathrm{F}} \mathrm{C}_{\mathrm{e}}^{1 / \mathrm{n}}$

$\mathrm{Q}_{\mathrm{e}}=\frac{\mathrm{b}_{1}\left(\mathrm{~K}_{1} \mathrm{C}_{\mathrm{e}}\right)^{\mathrm{n}_{1}}}{1+\left(\mathrm{K}_{1} \mathrm{C}_{\mathrm{e}}\right)^{\mathrm{n}_{1}}}$

$\mathrm{Q}_{\mathrm{e}}=\frac{\mathrm{b}_{1}\left(\mathrm{~K}_{1} \mathrm{C}_{\mathrm{e}}\right)^{\mathrm{n}_{1}}}{1+\left(\mathrm{K}_{1} \mathrm{C}_{\mathrm{e}}\right)^{\mathrm{n}_{1}}}+\frac{\mathrm{b}_{2}\left(\mathrm{~K}_{2} \mathrm{C}_{\mathrm{e}}\right)^{\mathrm{n}_{2}}}{1+\left(\mathrm{K}_{2} \mathrm{C}_{\mathrm{e}}\right)^{\mathrm{n}_{2}}}$

where $Q_{\mathrm{e}}$ : equilibrium sorption capacity $\left(\mathrm{mg} \mathrm{g}^{-1}\right)$; $\mathrm{C}_{\mathrm{e}}$ : equilibrium concentration of the solution $\left(\mathrm{mg} \mathrm{L}^{-1}\right)$; $\mathrm{K}_{\mathrm{L}}$ : Langmuir sorption constant $\left(\mathrm{L} \mathrm{mg}^{-1}\right) ; \mathrm{K}_{\mathrm{F}}$ : Freundlich constant related to sorption capacity $\left(\mathrm{mg} \mathrm{g}^{-1}\right)\left(\mathrm{L} \mathrm{g}^{-1}\right) ; \mathrm{K}_{1}$ : rate constant of pseudo-first-order adsorption process $\left(\mathrm{min}^{-1}\right)$; $\mathrm{K}_{2}$ : kinetic constant of pseudo-second-order adsorption $\left(\min ^{-1}\right) ; \mathrm{n}$ : constant related to sorption intensity or degree of sorption; $\mathrm{n}_{1}$ and $\mathrm{n}_{2}$ : heterogeneity factors and $\mathrm{b}$ : constant related to the maximum sorption capacity $\left(\mathrm{mg} \mathrm{g}^{-1}\right)$.

Thermodynamic parameters such as adsorption enthalpy $(\Delta \mathrm{H})$, entropy $(\Delta \mathrm{S})$ and Gibbs free energy $(\Delta \mathrm{G})$ were performed by stirring batch adsorption assays where $40 \mathrm{mg}$ of HMIP were weighed with a CAF solution $50 \mathrm{mg} \mathrm{L}^{-1}$ for $2 \mathrm{~h}$ at different temperatures (283.15, 293.15, $303.15,313.15$ and $323.15 \mathrm{~K}$ ). The solutions were analyzed by HPLC-UV and the parameters were estimated by equations 9 and $10 .^{7,11,15}$

$\ln \mathrm{K}_{\mathrm{d}}=\left(\frac{\Delta \mathrm{H}}{\mathrm{R}}\right) \frac{1}{\mathrm{~T}}+\left(\frac{\Delta \mathrm{S}}{\mathrm{R}}\right)$

$\Delta \mathrm{G}=\Delta \mathrm{H}-\mathrm{T} \Delta \mathrm{S}$

where $\mathrm{K}_{\mathrm{d}}$ : distribution constant, $\mathrm{R}$ : universal gas constant $\left(8.314 \mathrm{~J} \mathrm{~K}^{-1} \mathrm{~mol}^{-1}\right)$ and $\mathrm{T}$ : temperature $(\mathrm{K})$.

\section{Selectivity}

HMIP selectivity was evaluated by competitive sorption experiments with a ternary solution containing $10.0 \mathrm{mg} \mathrm{L}^{-1}$ of CAF and the analogous molecules theophylline (TEP) and theobromine (TEB). The selectivity test was performed under sorption equilibrium ( $2 \mathrm{~h}$ ) using $40 \mathrm{mg}$ of HMIP and HNIP, stirred in aqueous solutions containing $10 \mathrm{~mL}$ of the 
ternary solution. Supernatants were analyzed according to item described above.

From the competitive sorption between the structural analogs of the CAF, the distribution constant $\left(\mathrm{K}_{\mathrm{d}}\right)$, the selectivity coefficient $(\mathrm{k})$ and the relative selectivity coefficient $\left(\mathrm{k}^{\prime}\right)$ were determined, according to equations 11 , 12 and $13 .^{7}$

$\mathrm{K}_{\mathrm{d}}=\left(\frac{\mathrm{C}_{\mathrm{i}}-\mathrm{C}_{\mathrm{f}}}{\mathrm{C}_{\mathrm{f}}}\right) \times\left(\frac{\mathrm{V}_{(\mathrm{ml})}}{\mathrm{m}_{(\mathrm{g})}}\right)$

$\mathrm{k}=\left(\frac{\mathrm{Kd}_{\mathrm{CAF}}}{\mathrm{Kd}_{\text {analogue }}}\right)$

$\mathrm{k}^{\prime}=\left(\frac{\mathrm{k}_{\mathrm{HMIP}}}{\mathrm{k}_{\mathrm{HNIP}}}\right)$

The $K_{d}$ value describes how the species are distributed in the polymer matrix. The variables $\mathrm{C}_{\mathrm{i}}, \mathrm{C}_{\mathrm{f}}, \mathrm{V}$ and $\mathrm{m}$ represent the initial and final concentrations, the solution volumes in milliliters and the polymer mass in grams, respectively. The $k$ parameter expresses the distribution coefficient of the $\mathrm{K}_{\mathrm{d}}$ for CAF in relation to the $K_{d}$ of the analogous molecules. In addition, $\mathrm{k}$ ' represents the ratio between $\mathrm{k}$ estimated for HMIP and $\mathrm{k}$ obtained for HNIP with the same interferent.

\section{Regeneration studies}

To investigate the economic viability of HMIP, a reusability study was realized to verify the capacity of sorption process regeneration. For each cycle, $40 \mathrm{mg}$ was weighed in Falcon tubes $(\mathrm{n}=3)$ and $10 \mathrm{~mL}$ of $1.0 \mathrm{mg} \mathrm{L}^{-1}$ CAF solution were added. The tubes were placed in a mechanical shaker for $2 \mathrm{~h}$ and the solutions centrifuged for $20 \mathrm{~min}$ and the supernatant was analyzed. Desorption consisted of removal of the supernatant, followed by the addition of $3.00 \mathrm{~mL}$ of methanol and then the tubes were sonicated for $20 \mathrm{~min}(\mathrm{n}=3)$. The solvent fractions were combined and evaporated using a concentrator. The substances were resuspended in $2.0 \mathrm{~mL}$ of ultrapure water and further filtered using a $0.22 \mu \mathrm{m}$ pore size polyvinylidene syringe filter for HPLC-UV analysis. The desorption ratio was determined from equation 14 .

Desorption ratio $(\%)=\left(\frac{\text { amount of CAF desorbed }}{\text { amount of CAF addesorbed }}\right) \times 100$

\section{MISPE procedure for CAF extraction in surface water}

Surface water samples $(n=3)$ were collected at two points of Lake Paranoa (Brasília-DF) in a polytetrafluoroethylene
(PTFE) bottle that was previously washed with the own sample and transported to the laboratory in a cooler box, filtered through $0.47 \mu \mathrm{m}$ membrane filter stored in refrigerator at $4{ }^{\circ} \mathrm{C}$ until analysis, no longer than $24 \mathrm{~h} .{ }^{1}$

A $5 \mathrm{~mL}$ syringes was used as SPE cartridges and a disk of sintered polyethylene (fritz) was placed at the base of the syringe (outflow). Then, $300 \mathrm{mg}$ of HMIP was added to the syringe and on top, another fritz to accommodate the solid phase. The MISPE cartridge was connected to a peristaltic pump by the outlet tip with a Vitton tube. The procedure was adapted from literature ${ }^{13,28,29}$ that consisted of a conditioning step with $3 \mathrm{~mL}$ of methanol, followed by $3 \mathrm{~mL}$ of ultrapure water, followed by the addition of $500 \mathrm{~mL}$ of sample at a flow rate of $0.5 \mathrm{~mL} \mathrm{~min}{ }^{-1}$. In the washing step, $1.5 \mathrm{~mL}$ of distilled water was percolated, then the cartridges were dried, and the CAF was eluted with $2 \mathrm{~mL}$ of methanol that was analyzed by HPLC-UV. Ternary solutions, containing $20.0 \mu \mathrm{g} \mathrm{L}^{-1} \mathrm{CAF}$, TEF and TEB, were also carried out in MISPE procedure for selectivity evaluation. The accuracy was estimated by recovery tests with addition of two concentration levels (10.0 and $20.0 \mu \mathrm{g} \mathrm{L}^{-1} \mathrm{CAF}, \mathrm{n}=3$ ) in $500 \mathrm{~mL}$ of lake samples.

\section{Results and Discussion}

\section{Factorial design for HMIP synthesis}

For $p$ values (probability) of the estimated effects for the linear term, values of $0.006449,0.01167$ and 0.1444155 were obtained for the catalysts, FM and CL, respectively. According to the Pareto chart (Figure 1), the CL did not present significance at the 0.05 level, but their interactions proved to be significant. The catalyst at level +1 (basic catalyst) was a decisive factor for IF as it conducts a nucleophilic attack on silicon enabling better interconnection of the primary particles, resulting in spherical growth of the gel from the center of the oligomers. Thus, the colloidal gel will probably have a higher porosity polymeric matrix, with the possibility of presenting a larger number of selective sites in the polymer. ${ }^{22,30}$

Using the basic catalyst, a factorial design $2^{2}$ was made, with triplicate at the central point, to evaluate the proportion of FM and $C L$ as a function of IF. The value of the coefficient of determination $\mathrm{R}^{2}$ found was 0.99 , indicating that the quadratic model represents the interaction between effects and response. Figure 2 shows that both reagents at lower levels (-1) presented high IF. Through analysis of variance, the values of the $F_{\text {calculated }}$ distribution for the residuals in relation to regression were 30 times higher than the value of the $F_{\text {tab }}$ distribution at a confidence level of $95 \%$. This confirms that the regression was significant and could be 


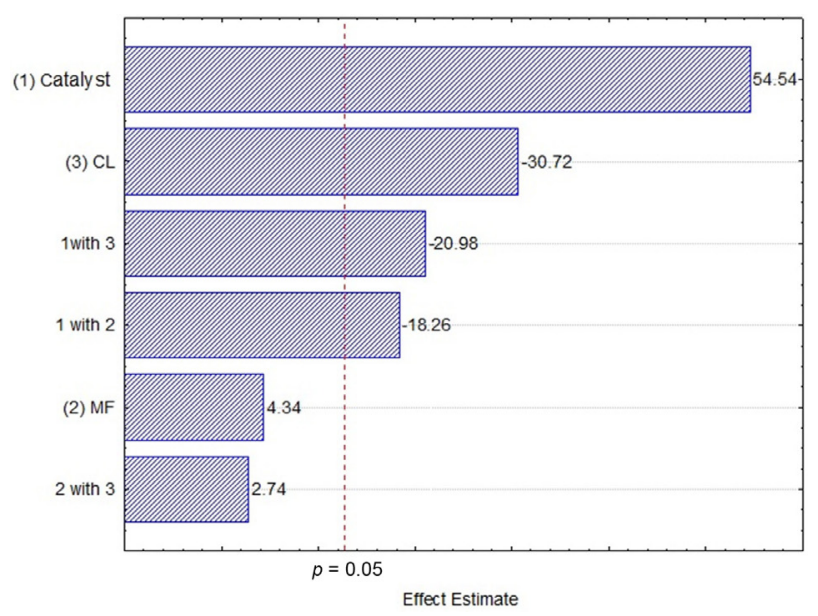

Figure 1. Pareto chart (CL, FM and catalyst) to significant effects ( $t$, $95 \%$ ) for impression factor.

used for prediction purposes. The change from level -1 to +1 and the fact that $C L$ and FM had a negative effect on IF, where the ratio 1:4 FM:CL resulted in an increase of $\mathrm{IF}^{31}$ This result was different from organic polymers, where this proportion is generally higher. From the results obtained by the factorial design, the synthesis of the HMIP was carried out as detailed in "HMIP synthesis" sub-section considering $4 \mathrm{mmol}$ CAF, $2 \mathrm{mmol}$ APTMS, $8 \mathrm{mmol}$ TEOS in a basic medium adjusted with $200 \mu \mathrm{L} \mathrm{NH}_{4} \mathrm{OH}$.

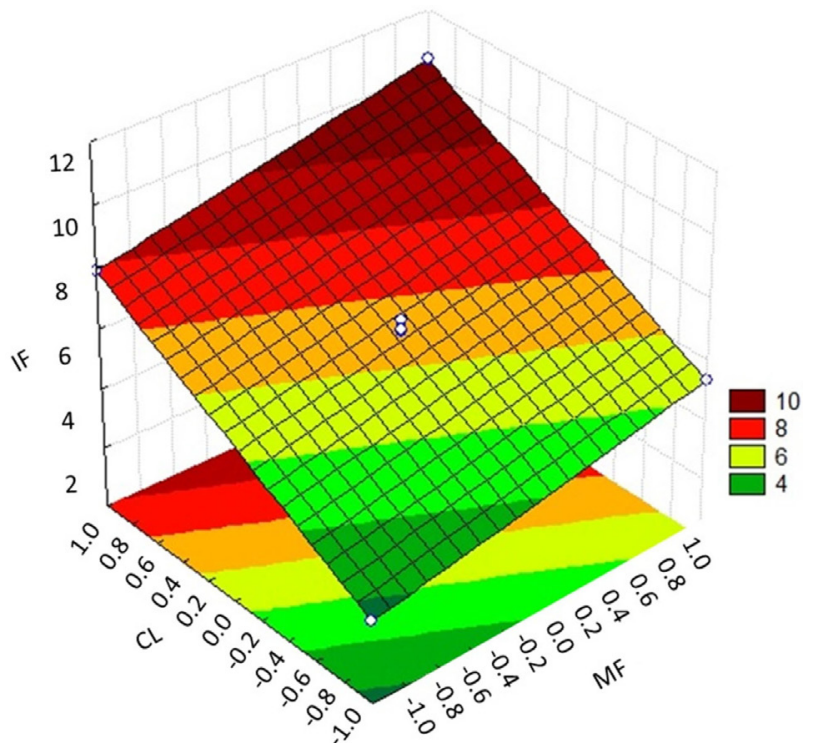

Figure 2. Response surface graph of the effect of the ratio of FM (functional monomer) to CL (cross-linker) on the impression factor (IF).

\section{Chemical and structural characterization of polymers}

The HMIPs and HNIPs were characterized by FTIR, thermogravimetric analysis (TGA) and SEM techniques. The FTIR spectra of the polymers are shown in Figure 3. The stretching vibrations observed in the hydroxyl groups $\left(3420 \mathrm{~cm}^{-1}\right)$ indicate the axial deformation vibration of the hydroxyl of the $\mathrm{Si}-\mathrm{OH}$ group. Bands at $2930 \mathrm{~cm}^{-1}$ are associated with persistent double bonds in the polymer chains. At $1639 \mathrm{~cm}^{-1}$ a band appears that can be attributed to the deformations of the $\mathrm{C}-\mathrm{H}$ groups, in addition to the band $1380 \mathrm{~cm}^{-1}$, which refers to the primary amine stretch present in (APTMS) and TEOS. The $761 \mathrm{~cm}^{-1}$ band can be attributed to free silanol $(\mathrm{Si}-\mathrm{OH})$ groups, like the sol-gel synthesis developed by Yang et al..$^{32}$ The $\mathrm{Si}-\mathrm{O}-\mathrm{Si}$ group presents a band at approximately $470 \mathrm{~cm}^{-1}$ indicating its deformation and an intense band at $1070 \mathrm{~cm}^{-1}$ with asymmetric stretching, suggesting a dense silicon and oxygen network, as observed by Jin and Tang. ${ }^{31}$ FTIR data demonstrate the successful formation of hybrid polymers though of bonding of organic and silanol groups.

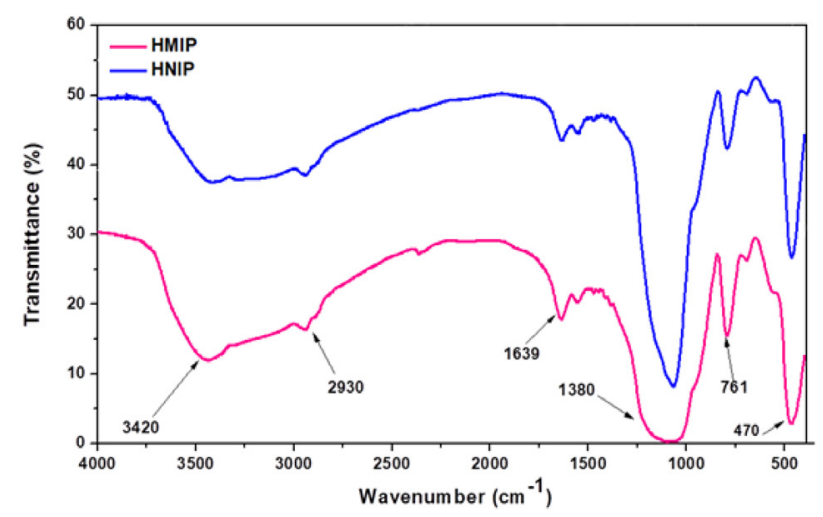

Figure 3. Infrared (attenuated total reflection (ATR)) absorption spectrum of HMIP and HNIP.

Thermogravimetric curves demonstrated (Figure 4) that hybrid polymers exhibited thermal stability with two mass loss regions. The first occurred at $50{ }^{\circ} \mathrm{C}$ due to the vaporization of polymerization products that had been sorbed or occluded in the material. Above $300{ }^{\circ} \mathrm{C}$ there was a prominent mass loss caused by the degradation of organic matter, hydroxyl groups and silane (dihydroxylation) with siloxane formation. Therefore, $300{ }^{\circ} \mathrm{C}$ may be considered as the limit temperature for a possible application involving the thermal desorption of analytes. These results demonstrated that the HMIP is adequate for application in aqueous solutions for $\mathrm{CAF}$ extraction in environmental temperature.

According to Figure 5, HMIP had a noticeable and higher porosity than HNIP, which appeared to have a smoother, more compact surface with small irregular microparticle clusters. This corroborates with the porosimetry results (Table 2), which indicated that the HMIP presented a larger surface area and pore volume than the HNIP, suggesting the formation of imprinted cavities. This is due to the relatively three-dimensional cavity formed between the monomers and the template molecules during 


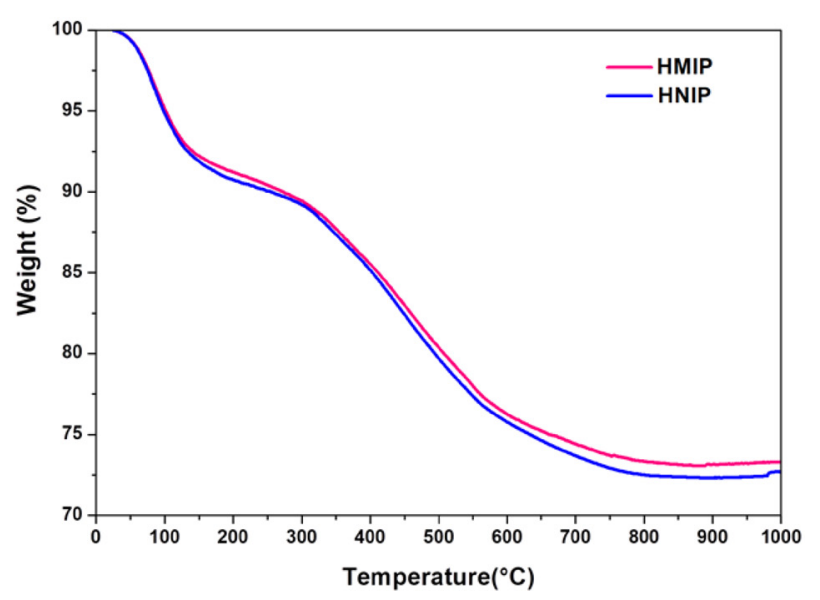

Figure 4. Thermogravimetric analysis (TGA) curves of HMIP and HNIP.

polymerization. ${ }^{33,34}$ The average pore diameter of the HMIP was higher than the control suggesting that the presence of CAF contributed mainly to the formation of the pores of the polymeric matrix by the hybrid sol-gel process. The data obtained revealed that HMIP is a mesoporous material according to the International Union of Pure and Applied Chemistry (IUPAC) definition, ${ }^{35}$ with an average pore diameter ranging from 2 to $50 \mathrm{~nm}$. Mesoporous materials are suitable for application in solid phase extraction as they promote adequate solvent permeability and diffusion of the target analytes.

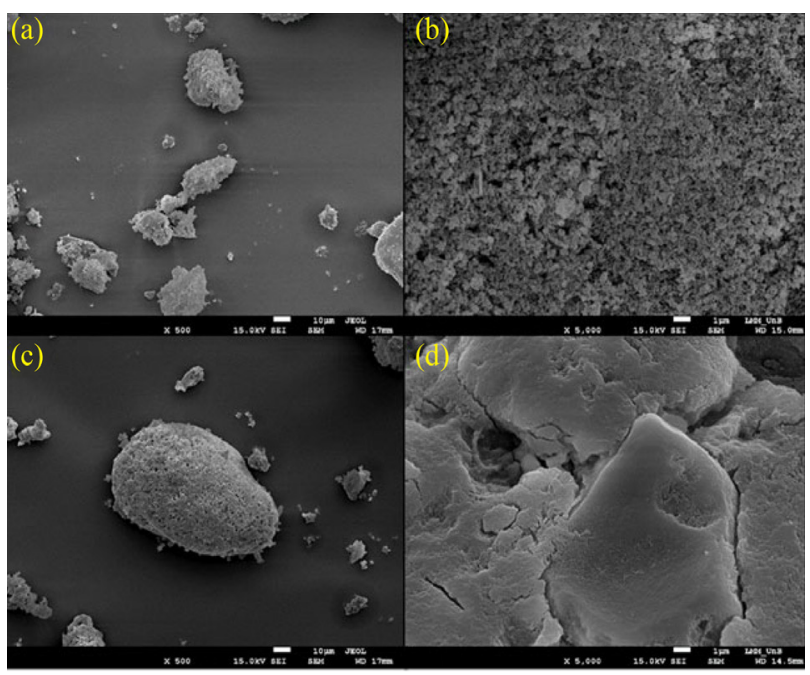

Figure 5. Scanning electronic micrographs of HMIP ( $a$ and b), HNIP (c and d). The images have been enlarged 500 and 5,000 times.

Table 2. Porosimetry results for HMIP and HNIP

\begin{tabular}{lccc}
\hline Polymer & $\begin{array}{c}\text { Surface area / } \\
\left(\mathrm{m}^{2} \mathrm{~g}^{-1}\right)\end{array}$ & $\begin{array}{c}\text { Average pore } \\
\text { diameter } / \AA\end{array}$ & $\begin{array}{c}\text { Pore volume / } \\
\left(\mathrm{cm}^{3} \mathrm{~g}^{-1}\right)\end{array}$ \\
\hline HMIP & 130.72 & 57.82 & 0.45 \\
HNIP & 28.37 & 38.38 & 0.08 \\
\hline
\end{tabular}

HMIP: hybrid imprinted polymer; HNIP: hybrid non-imprinted polymer.
Regarding the structural information described above, a possible mechanism of the HMIP synthesis is presented in Figure 6. The interactions between CAF and APTMS are based on hydrogen bonding formed between amine groups of APTMS and electronegative groups of CAF. Then, with the pre-polymerization complex formed, TEOS interacts with the available silane groups of APTMS during hydrolysis and condensation in the presence of a catalyst. As result, the polymer is formed and CAF is removed by methanol:acetic acid and the cavities are formed maintaining the amino groups available for the posterior CAF extraction.

\section{The effect of $\mathrm{pH}$ on caffeine sorption}

The $\mathrm{pH}$ effect of CAF sorption on HMIP was evaluated over a $\mathrm{pH}$ range of 3 to 9 . The amount of CAF sorbed increased about $5 \%$ with increasing $\mathrm{pH}$, reaching its maximum ( $80 \%$ sorption) at $\mathrm{pH} 7$. At a $\mathrm{pH}$ lower than 5, there was a $10 \%$ drop in sorption capacity, probably due to the amino group protonation that impaired the bond with CAF. When the $\mathrm{pH}$ was between 5 and 7 , more hydrogen bonds formed between the highly deprotonated CAF amino groups and the APTMS active groups. ${ }^{6,29}$ Under this condition, the $\mathrm{pH}$ of the sample solution have a direct effect on caffeine extraction efficiency and should be controlled. In view of these observations, for the other experiments, extractions were conducted at $\mathrm{pH}$ 7.0. This value is adequate to direct application in water samples without $\mathrm{pH}$ adjustment. The lake water, used as application in this work, obtained a $\mathrm{pH}$ of 7.27 , measured after filtration and before analysis. It is important to highlight that it was not necessary adjust the sample $\mathrm{pH}$ after the sampling because it was maintained in a cooler box during the transportation and analyses were performed until $24 \mathrm{~h}$, which is a usual procedure for emerging contaminants determination. ${ }^{1}$

\section{Study of kinetics and sorption equilibrium}

Figure 7 shows the adsorptive capacity of polymers for caffeine as a function of time. The chemical equilibrium of adsorption was reached in $120 \mathrm{~min}$ for HMIP, while for HNIP, where non-selective adsorption occurs, a time of $60 \mathrm{~min}$ was needed. The adsorptive capacity at equilibrium was $0.7 \mathrm{mg} \mathrm{g}^{-1}$ for HMIP and $0.05 \mathrm{mg} \mathrm{g}^{-1}$ for HNIP, a 14-fold factor in CAF sorption, which represents an excellent solid phase for CAF. Even in a shorter interval adsorption time, $\mathrm{Q}_{\mathrm{e}}$ (HMIP) was very superior in comparison to $\mathrm{Q}_{\mathrm{e}}(\mathrm{HNIP})$, showing a versatile applicability in environmental samples, which has a wide range of $\mathrm{CAF}$ concentrations. 
<smiles>CO[Si](OC)(OC)OCCCN</smiles>

APTMS

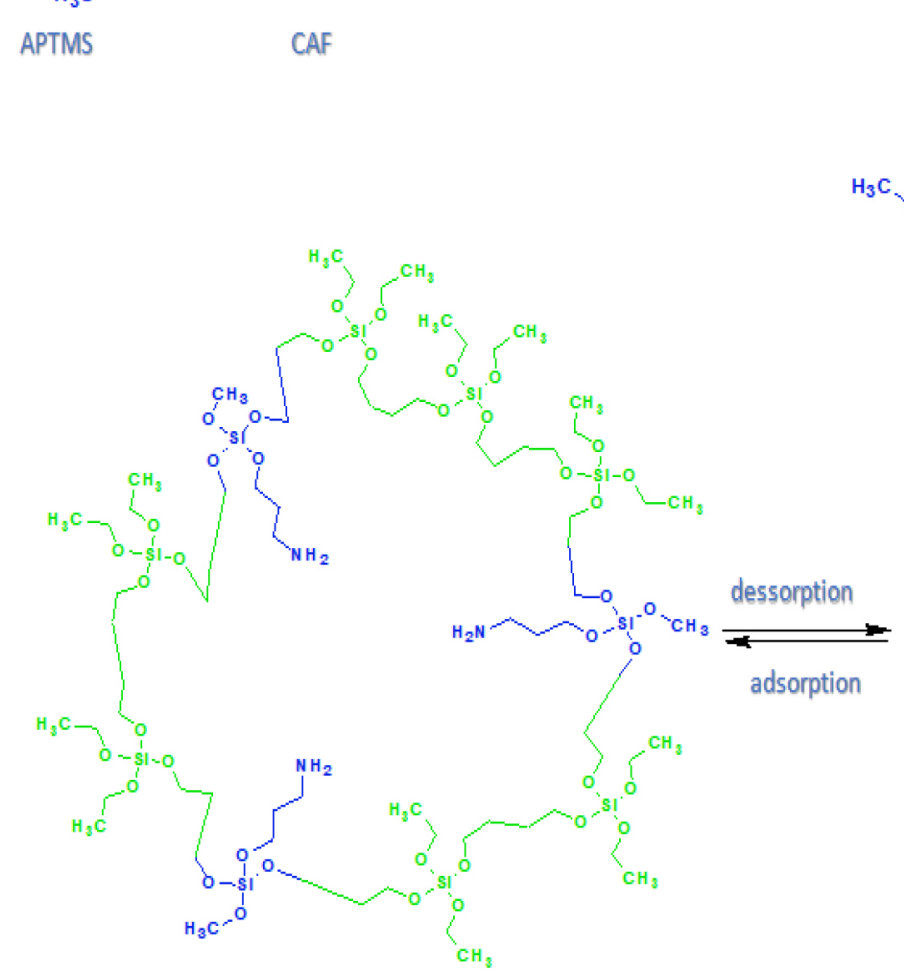

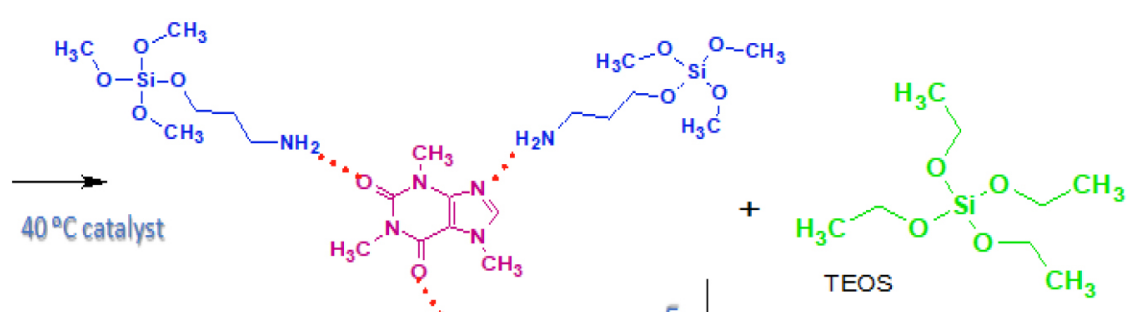

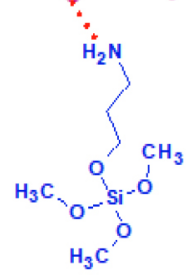

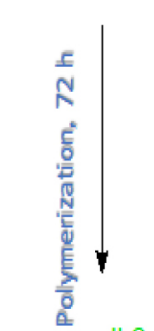

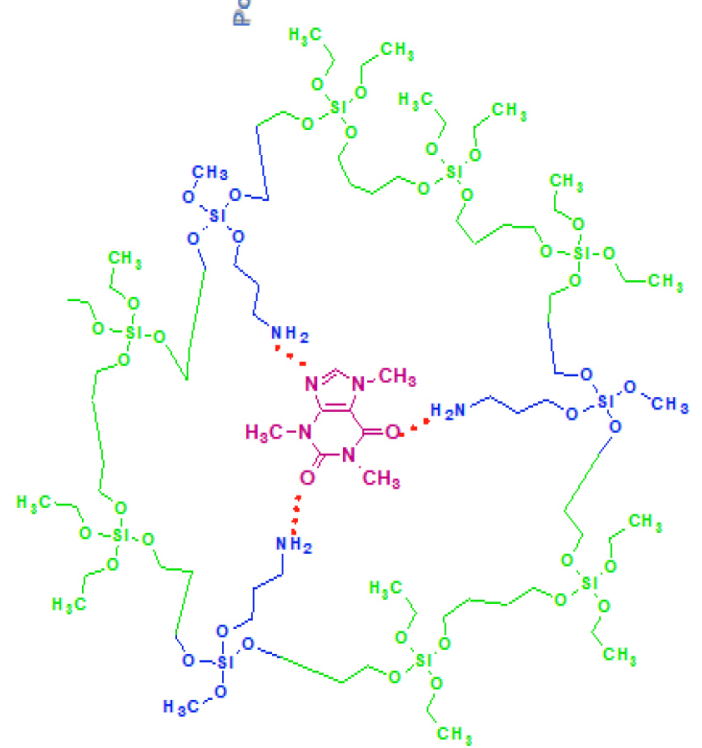

Figure 6. Mechanism proposed for HMIP synthesis. Steps of hydrolysis and polycondensation reaction between CAF-APTMS-TEOS, followed by removal of CAF and adsorption/extraction of CAF.

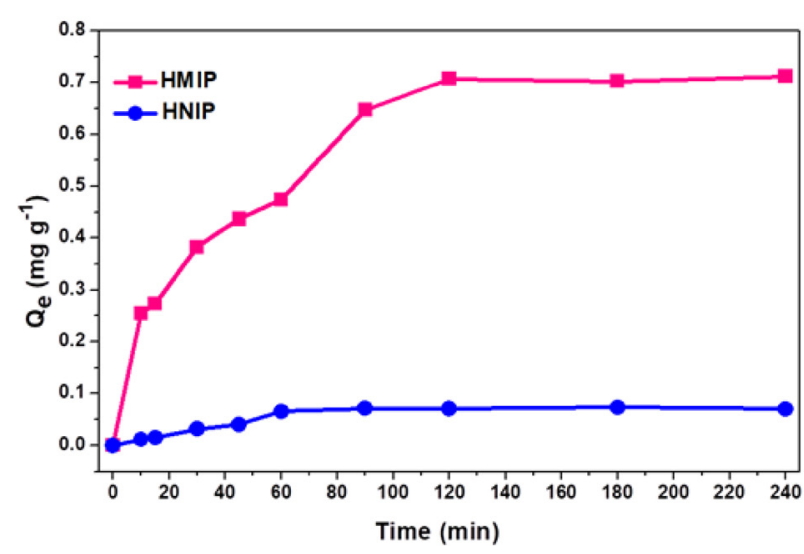

Figure 7. Influence of time on CAF sorption capacity by HMIP and HNIP.

The results obtained by pseudo-first order and pseudosecond order are described in Table 3. The model that presented adequate fit to the HMIP empirical data was the pseudo-second order adsorption model with a $\mathrm{K}_{2}$ with a HMIP value lower than HNIP. This can be explained by the fact that HMIP has cavities with specific interactions sites for
CAF, which results in a slow kinetic of adsorption, resulting in a slow mass transfer. Meanwhile, HNIP do not contain such cavities, becoming just a solid phase with nonspecific interactions. Furthermore, the pseudo-second order model also indicates a heterogeneous surface that indicates that the sorption process occurs in two sites with different binding energies. ${ }^{7,36} \mathrm{In}$ this model, the estimated values $\mathrm{Q}_{\mathrm{e}}\left(\mathrm{mg} \mathrm{L}^{-1}\right)$ for both polymers were notably close to those experimentally obtained at the same time of adsorption (20 min).

After established as $2 \mathrm{~h}$ the adsorption equilibrium, $\mathrm{Q}_{\mathrm{e}}$ was evaluated as a function of progressive CAF concentrations. Figure 8 shows that for HMIP, the $Q_{e}$ increased with the progressive addition of CAF. This profile was not the same observed for HNIP, showing again a nonspecific adsorption process. In the equilibrium, the IF was estimated as 22.5, proving that HMIP presents a remarkable adsorption capacity and high selectivity compared to the control polymer. Recent studies involving CAF adsorption have reported lower IF values than those obtained in this study, ranging from 1.7 to $20.5 .8,29,37-41$ 
Table 3. Kinetic parameters for HMIP and HNIP for CAF adsorption

\begin{tabular}{|c|c|c|c|c|c|c|}
\hline \multirow{3}{*}{ Polymer } & \multirow{2}{*}{\multicolumn{3}{|c|}{$\begin{array}{c}\text { Pseudo-first order } \\
\ln \left(Q_{e}-Q_{t}\right)=\ln Q_{e}-K_{1} t\end{array}$}} & \multicolumn{3}{|c|}{ Pseudo-second order } \\
\hline & & & & \multicolumn{3}{|c|}{$\frac{\mathrm{t}}{\mathrm{Q}_{\mathrm{t}}}=\frac{1}{\mathrm{~K}_{2} \mathrm{Q}_{\mathrm{e}}^{2}}+\frac{1}{\mathrm{Q}_{\mathrm{e}}} \mathrm{t}$} \\
\hline & $\mathrm{K}_{1} / \mathrm{min}^{-1}$ & $\mathrm{Q}_{\mathrm{e}} /\left(\mathrm{mg} \mathrm{g}^{-1}\right)$ & $\mathrm{R}^{2}$ & $\mathrm{~K}_{2} / \mathrm{min}^{-1}$ & $\mathrm{Q}_{\mathrm{e}} /\left(\mathrm{mg} \mathrm{g}^{-1}\right)$ & $\mathrm{R}^{2}$ \\
\hline HMIP & 0.019 & 0.477 & 0.90 & 0.054 & 0.770 & 0.99 \\
\hline HNIP & 0.003 & 0.080 & 0.66 & 0.290 & 0.086 & 0.90 \\
\hline
\end{tabular}

$\mathrm{Q}_{\mathrm{e}}$ : equilibrium sorption capacity; $\mathrm{Q}_{\mathrm{i}}$ : equilibrium sorption capacity at specific time, t: time of the study; $\mathrm{K}_{1}$ : rate constant of pseudo-first-order sorption process; $\mathrm{R}^{2}$ : coefficient of determination; $\mathrm{K}_{2}$ : kinetic constant of pseudo-second-order sorption; HMIP: hybrid imprinted polymer; HNIP: hybrid nonimprinted polymer.

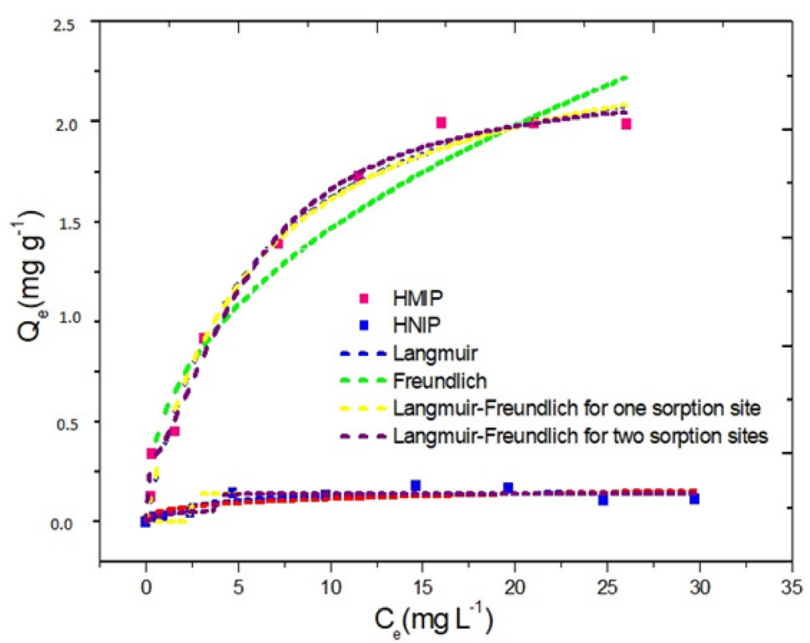

Figure 8. Experimental data obtained for the construction of the HMIP and HNIP sorption isotherms.

The adsorption thermodynamic parameters estimated are shown in Table 4. For HMIP the empirical data can be best described by the nonlinear Langmuir-Freundlich model for two sorption sites, which presented the best fit. This model suggests that there are homogeneous and heterogeneous sites with different bonding energies, such as chemisorption and physisorption mechanisms in monolayers and multilayers. ${ }^{6}$ The theoretical maximum sorption capacity of the imprinted polymer for CAF was $\mathrm{Q}_{\mathrm{e}}$ at $1.9 \mathrm{mg} \mathrm{g}^{-1}$, notably close to what had been obtained experimentally. These results corroborate with the results of the pseudo-second order kinetic model, indicating that the sorbent materials have sorption sites with different energies that will be estimated below.

\section{Thermodynamic parameters}

The value of $\Delta \mathrm{H}$ and $\Delta \mathrm{S}$ were obtained by a linear regression of $\operatorname{lnK}_{\mathrm{d}}$ versus $1 / \mathrm{T}$ as $-12.47 \mathrm{~kJ} \mathrm{~mol}^{-1}$ and $-8,7 \mathrm{~J} \mathrm{~mol}^{-1}$, respectively. The values for $\Delta \mathrm{G}$ were negative at all temperatures studied, indicating the spontaneous and

Table 4. Sorption isotherm parameters for HMIP and HNIP

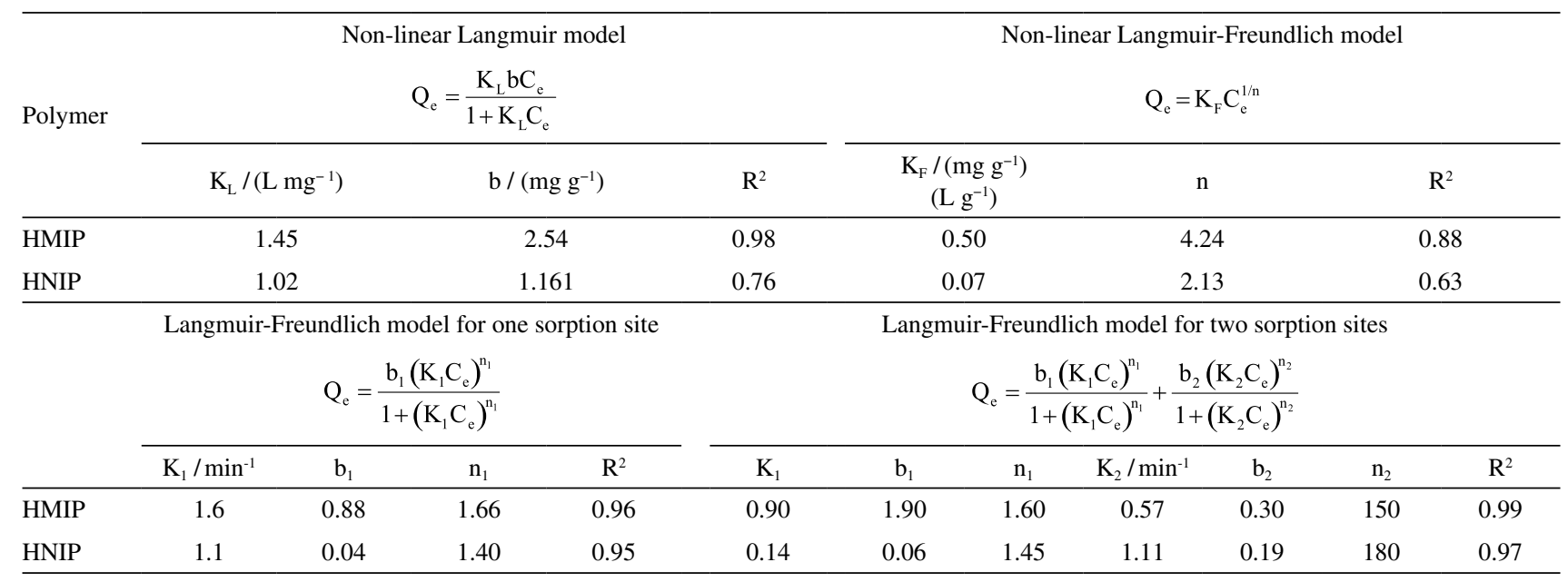

$\mathrm{Q}_{\mathrm{e}}$ : equilibrium sorption capacity; $\mathrm{C}_{\mathrm{e}}$ : equilibrium concentration of the solution $\left(\mathrm{mg} \mathrm{L}^{-1}\right) ; \mathrm{K}_{\mathrm{L}}$ : Langmuir sorption constant; b: constant related to the maximum sorption capacity; $\mathrm{R}^{2}$ : coefficient of determination; $\mathrm{K}_{\mathrm{F}}$ : Freundlich constant related to sorption capacity; $\mathrm{n}$ : constant related to sorption intensity or degree of sorption; $\mathrm{K}_{1}$ : rate constant of pseudo-first-order adsorption process; $\mathrm{K}_{2}$ : kinetic constant of pseudo-second-order adsorption; $\mathrm{n}_{1}$ and $\mathrm{n}_{2}$ : heterogeneity factors; $b_{1}$ and $b_{2}$ : maximum adsorption capacity constants. 
favorable nature of CAF sorption in HMIP. These values become more negative as the temperature decreases, demonstrating that under lower temperatures there may be a favoring of CAF sorption in the material. Negative $\Delta \mathrm{S}$ values indicate a decrease in sorbent-sorbate interface disorder during the CAF sorption process. The negative $\Delta \mathrm{H}$ indicates the exothermic nature of the sorption process. The magnitude of the $\Delta \mathrm{H}$ value gives us a more detailed view of the nature of the sorption binding energy and can predict the occurrence of hydrogen bonds ( 5 to $\left.20 \mathrm{~kJ} \mathrm{~mol}^{-1}\right)^{42}$ between the functional groups (amine and amide) present in the CAF and in APTMS. The linear correlation for the control polymers was low, representing inconclusive data for this study and thus, they are not presented.

\section{Selectivity studies}

The HMIP selectivity for CAF was evaluated by distribution constants and selectivity coefficients with a presence of its analogous molecules. Table 5 shows a higher $\mathrm{K}_{\mathrm{d}}$ value for CAF than TEP and TEB, suggesting that HMIP had higher affinity for CAF adsorption. The selectivity in relation to distribution coefficient was confirmed by the $\mathrm{k}$ values for TEP and TEB, that were 21.9 and 9.1, respectively. In comparison to control polymer (HNIP), a high k' value was obtained suggesting that CAF sorption occurs preferentially at HMIP selective sites and that the optimization study provided the most adequate selectivity material compared to the control polymer.

The IF obtained with this material was higher than those cited in literature for CAF extraction (Table 6). A similar result of IF was related by a sol-gel hybrid material, however, the material presented poor selectivity for theophylline $(\mathrm{k}=1.1)$ in comparison with this work $(\mathrm{k}=21.9)$, which limit the material application in complex samples. According to literature, most works discuss selectivity by IF and $\mathrm{Q}_{\mathrm{e}}$ values, without consider application of CAF analogues molecules. However, these parameters are not the most adequate to prove MIP selectivity, because even with high IF (20.5), a low k (1.1) can be observed and with a high $\mathrm{Q}_{\mathrm{e}}(62.7)$ a low IF (2.4) and $\mathrm{k}$ (2.5) values is also observed. ${ }^{29,38}$ Then, the superior value of IF (22.5) and $\mathrm{k}$ (21.9) obtained in this work shows that the factorial design method is a powerful tool to optimize interdependent variables, which resulted in formation of selective cavities for $\mathrm{CAF}$ in aqueous medium.

\section{Reusability and regeneration studies}

To investigate the performance of HMIP regeneration and reusability, the sorption and desorption cycles were

Table 5. Selectivity parameters for HMIP and HNIP

\begin{tabular}{|c|c|c|c|c|c|c|}
\hline \multirow{2}{*}{ Polymer } & \multicolumn{3}{|c|}{$\mathrm{K}_{\mathrm{d}} /\left(\mathrm{mL} \mathrm{g}^{-1}\right)$} & \multicolumn{2}{|c|}{$\mathrm{k}$} & \multirow{2}{*}{$\frac{\mathrm{k}^{\prime}}{\text { (HMIP/HNIP }}$} \\
\hline & CAF & TEP & TEB & TEP & TEB & \\
\hline HMIP & $24.53 \pm 0.02$ & $1.12 \pm 0.14$ & $2.71 \pm 0.01$ & 21.90 & 9.1 & 15.3 \\
\hline HNIP & $1.60 \pm 0.70$ & $3.85 \pm 0.80$ & $3.70 \pm 0.40$ & 0.96 & 2.3 & \\
\hline
\end{tabular}

$\mathrm{K}_{\mathrm{d}}$ : distribution constant; $\mathrm{k}$ : selectivity coefficient; $\mathrm{k}$ ': relative selectivity coefficient; CAF: caffeine; TEP: theophylline; TEB: theobromine; HMIP: hybrid imprinted polymer; HNIP: hybrid non-imprinted polymer.

Table 6. Comparison of selectivity, sorption capacity and recovery of MIP for CAF extraction found in the literature. Theophylline was considered in $\mathrm{k}$ values

\begin{tabular}{|c|c|c|c|c|c|c|c|}
\hline $\begin{array}{l}\text { Polymerization } \\
\text { process }\end{array}$ & Polymeric matrix & IF & $\mathrm{k}$ & $\mathrm{k}^{\prime}$ & Recovery / \% & $\mathrm{Q}_{\mathrm{e}} /\left(\mathrm{mg} \mathrm{g}^{-1}\right)$ & Reference \\
\hline Sol-gel & inorganic & - & 4.1 & - & - & 1.84 & 42 \\
\hline Sol-gel & hybrid & 20.5 & $1.1^{\mathrm{a}}$ & - & 85.0 & - & 29 \\
\hline Radical & organic & 1.5 & - & - & & 0.53 & 43 \\
\hline Radical & organic & 6.5 & - & - & - & 2.48 & 36 \\
\hline Radical & organic & 2.7 & - & - & - & 5.6 & 37 \\
\hline Radical & organic & 1.6 & 9.6 & - & $63.0-84.0$ & - & 8 \\
\hline Radical & organic & $2.4^{\mathrm{a}}$ & 2.5 & 2.75 & $91.3-99.2$ & 62.7 & 38 \\
\hline Radical & organic & $2.0^{\mathrm{a}}$ & - & - & - & 0.024 & 39 \\
\hline Sol-gel & hybrid & $10.0^{\mathrm{a}}$ & - & - & $77.0-82.0$ & - & 40 \\
\hline Sol-gel & hybrid & 22.5 & 21.9 & 15.3 & $92.0-93.0$ & 1.91 & this work \\
\hline
\end{tabular}

aEstimated by the authors according to the information cited in the reference work. IF: impression factor; k: selectivity coefficient; k': relative selectivity coefficient; $\mathrm{Q}_{\mathrm{e}}$ : amount of sorbent absorbed per gram of sorbate. 


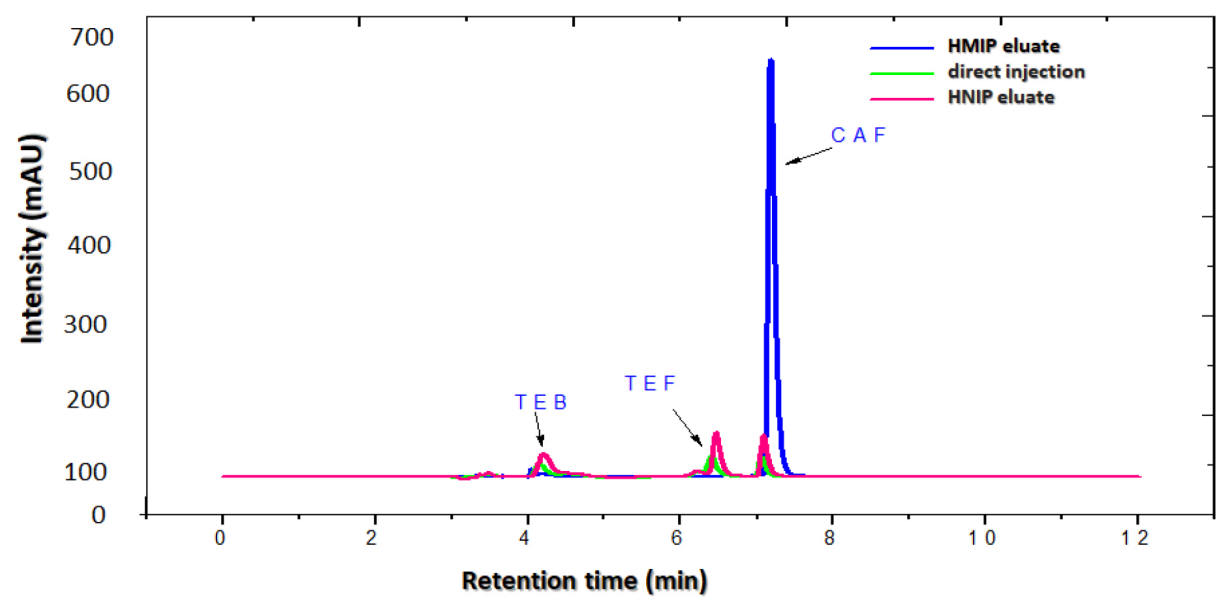

Figure 9. Chromatogram of the (-) HMIP, (-) HNIP and (-) direct injection.

repeated 13 times. Sorption/desorption capacity decreased slightly from 99.47 to $98.32 \%$ from cycle 10 to 11 , then 10 cycles was chosen as adequate reusability with unchanged sorption efficiency. The cost per extraction procedure was estimated at US\$ 0.21 considering the reusability of 10 times. This value is less than extraction procedures in commercial SPE cartridges that are not reusable. For a comparison of these parameters with literature, it was not found costs values or reusability factor in the works cited in Table 6.

\section{MISPE procedure for CAF extraction in surface water}

MISPE procedure was applied considering that the SPE procedures is the most sample preparation procedure used in analytical laboratories for water analysis. Furthermore, in SPE cartridges, the solid phase is confined in a small space, resulting in a solution preferential pathway, damaging the mass transfer mechanism and consequently, adsorption equilibrium to CAF extraction. Then, a ternary solution containing CAF, TEB and TEF was processed in HMISPE procedure to confirm the selectivity parameters. Figure 9 shows the chromatograms obtained for the direct injection of the ternary solution and after MIPSE procedure with a HMIP and HNIP as control. The sample profile presented low analytical signals for the three molecules. However, after the MISPE procedure its evident that caffeine was efficiently extracted with an increase in analytical signal magnitude due to the pre-concentration promoted by the procedure. The efficient extraction is also corroborated by the HNIP chromatogram, which presented low signal for $\mathrm{CAF}$ and presence of TEF and TEB, proving the absence of specific cavities. The sorption of these molecules in HNIP is due to the presence of unorganized functional groups that can interact by hydrogen bonding in an unorganized an unspecific way.
Samples of surface water from Lake Paranoá-DF fortified with 10.0 and $20.0 \mu \mathrm{g} \mathrm{L}^{-1} \mathrm{CAF}$ were processed in the MISPE procedure. The recovery results are described in Table 7 and were approximately $93 \%$ for the two concentrations. These results corroborate the accuracy and selectivity of the method to extract the CAF in complex environmental samples, such as those from surface waters. ${ }^{1}$

Table 7. Results of sample processing

\begin{tabular}{lccc}
\hline Sample & $\begin{array}{c}\text { CAF added / } \\
\left(\mu \mathrm{g} \mathrm{L}^{-1}\right)\end{array}$ & $\begin{array}{c}\mathrm{CAF} \text { found / } \\
\left(\mu \mathrm{g} \mathrm{L}^{-1}\right)\end{array}$ & Recovery / \% \\
\hline 1 & 0 & $0.039 \pm 0.001$ & - \\
2 & 10 & $9.30 \pm 0.036$ & $93.0 \pm 0.36$ \\
3 & 20 & $18.54 \pm 1.160$ & $92.7 \pm 0.58$ \\
\hline
\end{tabular}

CAF: caffeine.

\section{Conclusions}

The systematic investigation of the catalyst, hybrid functional monomer and crosslinker by experimental design was considered essential to determine the best synthesis conditions with minimal bench work and reagent consumption. With the best parameters determined by planning factorial design (basic catalyst, $\mathrm{NH}_{4} \mathrm{OH}$ ) and a FM:CL ratio $(1: 4 \mathrm{mmol})$, high values of selectivity parameters were obtained, as impression factor of 22.5 and $\mathrm{k}$ ' of 15.3, considering the analogous molecules. This is the first time that a deep selectivity study is shown for CAF extraction by using a hybrid molecular imprinted polymer. Besides that, the k' values were consistent with IF and $\mathrm{K}_{\mathrm{d}}$, showing that the CAF distribution was efficient.

Regarding adsorption and kinetics isotherms, it can be observed that CAF adsorption in HMIP surface, occurs in two sites with different energies, near hydrogen bonds, 
in a spontaneous process. The mechanism adsorption and desorption could be realized until ten cycles, without loss, which makes it economically viable.

Application of MISPE procedure, with the HMIP as solid phase, obtained excellent results for CAF recovery (93.0\%), indicating the absence of matrix effect with a perspective to be applied in a wide range of samples for CAF determination.

\section{Acknowledgments}

The authors thank CNPQ for doctoral fellowship, FAPDF (process No. 0193.001046/2015), INCTAA, Institute of Chemistry and University of Brasília for the financial support.

\section{Author Contributions}

F. Casarin, C. S. Dourado, L. S. Sousa, M. T. Grassi, A C. B. Dias were responsible for conceptualization, data curation, investigation and validation; F. Casarin, A. C. B. Dias, M. T. Grassi, for writing original draft, writing-review and editing; A. C. B. Dias for formal analysis funding acquisition, project administration and resources.

\section{References}

1. Montagner, C. C.; Sodré, F. F.; Acayaba, R. D.; Vidal, C.; Campestrini, I.; Locatelli, M. A.; Pescara, I. C.; Albuquerque, A. F.; Umbuzeiro, G. A.; Jardim, W. F.; J. Braz. Chem. Soc. 2019, 30, 614.

2. Gardinali, P. R.; Zhao, X.; Environ. Int. 2002, 28, 521.

3. Machado, K. C.; Grassi, M. T.; Vidal, C.; Pescara, I. C.; Jardim, W. F.; Fernandes, A. N.; Sodré, F. F.; Almeida, F. V.; Santana, J. S.; Canela, M. C.; Nunes, C. R. O.; Bichinho, K. M.; Severo, F. J. R.; Sci. Total Environ. 2016, 572, 138.

4. Campanha, M. B.; Awan, A. T.; de Sousa, D. N. R.; Grosseli, G. M.; Mozeto, A. A.; Fadini, P. S.; Environ. Sci. Pollut. Res. 2014, 22, 7936.

5. Ma, R.; Wang, B.; Yin, L.; Zhang, Y.; Deng, S.; Huang, J.; Wang, Y.; Yu, G.; J. Hazard. Mater. 2017, 323, 147.

6. Casarin, J.; Gonçalves Jr., A. C.; Segatelli, M. G.; Tarley, C. R. T.; React. Funct. Polym. 2017, 121, 101.

7. Casarin, J.; Gonçalves Jr., A. C.; Segatelli, M. G.; Tarley, C. R. T.; Chem. Eng. J. 2018, 343, 583.

8. Lim, K. F.; Holdsworth, C. I.; Molecules 2018, 23, 2996.

9. Tarley, C. R. T.; Sotomayor, M. D. P. T.; Kubota, L. T.; Quim. Nova 2005, 28, 1076.

10. Özkahraman, B.; Özbaş, Z.; Bal Öztürk, A.; J. Polym. Environ. 2018, 26, 4303.

11. Özkahraman, B.; J. Polym. Environ. 2018, 26, 1113.
12. Marestoni, L. D.; Sotomayor, M. D. P. T.; Segatelli, M. G.; Sartori, L. R.; Tarley, C. R. T.; Quim. Nova 2013, 36, 1194.

13. Liu, X.; Sun, N.; Zhu, Q.; Wu, M.; Ye, Y.; Chen, H.; J. Chromatogr. A 2013, 1304, 10.

14. Mayes, A. G.; Whitcombe, M. J.; Adv. Drug Delivery Rev. 2005, 57, 1742 .

15. da Mata, K.; Corazza, M. Z.; de Oliveira, F. M.; de Toffoli, A. L.; Tarley, C. R. T.; Moreira, A. B.; React. Funct. Polym. 2014, $83,76$.

16. Santos, M. G.; Abrão, L. C. D. C.; Freitas, L. A. D. S.; Moraes, G. D. O. I.; de Lima, M. M.; Figueiredo, E. C.; Sci. Chromatogr. 2012, 4, 161.

17. Abd Rahim, M.; Wan Ibrahim, W. A.; Ramli, Z.; Sanagi, M. M.; Aboul-Enein, H. Y.; Chromatographia 2016, 79, 421.

18. Masini, J. C.; Svec, F.; Anal. Chim. Acta 2017, 964, 24.

19. Braga, L. R.; Rosa, A. A.; Dias, A. C. B.; Anal. Methods 2014, 6, 4029.

20. Deng, N.; Liang, Z.; Liang, Y.; Sui, Z.; Zhang, L.; Wu, Q.; Yang, K.; Zhang, L.; Zhang, Y.; Anal. Chem. 2012, 84, 10186.

21. José, N. M.; Prado, L. A. S. A.; Quim. Nova 2005, 28, 281.

22. Benvenutti, E. V.; Moro, C. C.; Costa, T. M. H.; Gallas, M. R.; Quim. Nova 2009, 32, 1926.

23. Boulanouar, S.; Mezzache, S.; Combès, A.; Pichon, V.; Talanta 2018, 176, 465.

24. Davies, M. P.; de Biasi, V.; Perrett, D.; Anal. Chim. Acta 2004, $504,7$.

25. Salimraftar, N.; Noee, S.; Abdouss, M.; Riazi, G.; Khoshhesab, Z. M.; Polym. Bull. 2014, 71, 19.

26. Guardia, L.; Badía, R.; Granda-Valdés, M.; Díaz-García, M. E.; J. Sol-Gel Sci. Technol. 2012, 63, 537.

27. Statistica version 7.0; Statsoft, INC, Carlile, MA, USA, 2004.

28. https://bdm.unb.br/handle/10483/23862, accessed in March 2021.

29. da Costa Silva, R. G.; Augusto, F.; J. Chromatogr. A 2006, 1114, 216.

30. Ashley, J.; Shahbazi, M.-A.; Kant, K.; Chidambara, V. A.; Wolff, A.; Bang, D. D.; Sun, Y.; Biosens. Bioelectron. 2017, 91, 606.

31. Jin, G.; Tang, Y.; Microchim. Acta 2009, 165, 143.

32. Yang, J.; Li, Y.; Wang, J.; Sun, X.; Shah, S. M.; Cao, R.; Chen, J.; Anal. Chim. Acta 2015, 853, 311.

33. Samanidou, V.; Kehagia, M.; Kabir, A.; Furton, K. G.; Anal. Chim. Acta 2016, 914, 62.

34. Chrzanowska, A. M.; Poliwoda, A.; Wieczorek, P. P.; J. Chromatogr. A 2015, 1392, 1.

35. IUPAC; Pure Appl. Chem. 1994, 66, 1739.

36. Elshafei, G. S.; Nasr, I. N.; Hassan, A. S. M.; Mohammad, S. G. M.; J. Hazard. Mater. 2009, 172, 1608.

37. Luo, X.; Dong, R.; Luo, S.; Zhan, Y.; Tu, X.; Yang, L.; Appl. Polym. 2013, 2884.

38. Zhou, Y.; Xiong, L.; Lu, F.; Adv. Polym. Technol. 2015, 36, 1. 
39. Dong, Y.; He, L. F.; Zhang, X. H.; Jiang, X. R.; Dig. J. Nanomater. Bios. 2016, 11, 1319.

40. Manzoor, S.; Rossi, A. V.; Buffon, R.; Sep. Sci. Technol. 2018, 53, 877.

41. Nayibe, L.; Saavedra, M.; Eduardo, B.; Baeta, L.; César, M.; Carlos, L.; de Oliveira, A.; Candido, A.; Fuel 2017, 210, 380.
42. Wei, H.-S.; Tsai, Y. L.; Wu, J. Y.; Chen, H.; J. Chromatogr. B: Anal. Technol. Biomed. Life Sci. 2006, 836, 57.

43. Oliveira, D.; Freitas, A.; Kadhirvel, P.; Dias, R. C. S.; Costa, M. R. P. F. N.; Biochem. Eng. J. 2016, 111, 87.

Submitted: January 2, 2021 Published online: May 10, 2021 